\title{
A sorrow shared is a sorrow halved? A three-arm randomized controlled trial comparing internet-based clinician-guided individual versus group treatment for social anxiety disorder
}

Ava Schulz ${ }^{\mathrm{a}}$, Timo Stolz ${ }^{\mathrm{a}}$, Alessia Vincent ${ }^{\mathrm{a}}$, Tobias Kriegerª ${ }^{\mathrm{a}}$ Gerhard Andersson ${ }^{\mathrm{b}, \mathrm{c}}$ \& Thomas Bergera

a Department of Clinical Psychology and Psychotherapy, University of Bern, Fabrikstrasse 8, 3012 Bern, Switzerland

b Behavioural Sciences and Learning, Swedish Institute for Disability Research, Linköping University, Campus Valla I:3, SE-581 83, Linköping, Sweden

c Department of Clinical Neuroscience, Psychiatry Section, Karolinska Institutet, Tomtebodavägen 18A, 17177 Stockholm, Sweden

${ }^{*}$ Corresponding author

Email addresses:

AS: ava.schulz@psy.unibe.ch

TS: timo.stolz@psy.unibe.ch

AV: alessia.vincent@students.unibe.ch

TK: tobias.krieger@psy.unibe.ch

GA : gerhard.andersson@liu.se

TB: thomas.berger@ptp.unibe.ch 
Abstract

A growing body of evidence suggests that internet-based cognitive behavioural treatments (ICBT) are effective to treat social anxiety disorder (SAD). Whereas the efficacy of clinician-guided ICBT has been established, ICBT in a group format has not yet been systematically investigated. This three-arm RCT compared the efficacy of clinician-guided group ICBT (GT) with clinician guided individual ICBT (IT) and a waitlist (WL). A total of 149 individuals meeting the diagnostic criteria for SAD were randomly assigned to one of three conditions. Primary endpoints were self-report measures of SAD and diagnostic status taken at baseline, after the twelve-week intervention and at six-month follow-up. Secondary endpoints were symptoms of depression, interpersonal problems and general symptomatology. At post-treatment, both active conditions showed superior outcome regarding SAD symptoms (GT vs. WL: $d=0.84-0.74$; IT vs. WL: $d=0.94-1.22$ ). The two active conditions did not differ significantly in symptom reduction $(d=0.12-0.26$, all $p s>0.63)$, diagnostic response rate or attrition. Treatment gains were maintained at follow-up. The group format reduced weekly therapist time per participant by $71 \%$ (IT: $17 \mathrm{~min}, \mathrm{GT}: 5 \mathrm{~min}$ ). Findings indicate that a clinician-guided group format is a promising approach in treating SAD.

Keywords: Internet treatment, ICBT, social anxiety disorder, guided self-help, group therapy, peer support, $R C T$ 
A sorrow shared is a sorrow halved? A three-arm randomized controlled trial comparing internet-based individual versus group treatment for social anxiety disorder The field of internet-based cognitive behavioural treatments (ICBT) ${ }^{1}$ for mental health problems has grown rapidly during the last decade. Most of the growing body of evidence comes from studies evaluating guided ICBT, in which the presentation of a web-based self-help program is combined with minimal but regular therapist contact via secured e-mail (Berger \& Andersson, 2009). The efficacy of this treatment format has been demonstrated for a variety of mental disorders in a number of randomized controlled trials (RCTs) and meta-analyses (e.g. Hedman, Ljotsson, \& Lindefors, 2012). Studies directly comparing internet interventions with face-to-face therapy report similar outcomes across various mental disorders (e.g., anxiety disorders, depression) and health concerns associated with bodily symptoms (e.g. tinnitus, sexual dysfunction; Andersson, Cuijpers, Carlbring, Riper, and Hedman, 2014). Moreover, long-term followup studies show lasting effects over as much as five years (e.g. Hedman, Furmark, et al., 2011).

Social anxiety disorder (SAD) is one of the clinical fields where research on ICBT has been most extensive during the last decade and it is likely that SAD is the disorder for which this type of treatment has the strongest empirical support (Boettcher, Carlbring, Renneberg, \& Berger, 2013; Hedman, Botella, \& Berger, 2016). SAD is characterized by a marked and persistent fear of being scrutinized and negatively judged by others in social or performance situations (American Psychiatric Association, 2013). SAD is the third most common mental disorder with an estimated lifetime

\footnotetext{
${ }^{1}$ Abbreviations: ICBT: Internet-based cognitive behavioural treatment; SAD: social anxiety disorder; IT: clinician-guided individual treatment; GT: clinician-guided group treatment; WL: wait-list; SPS: Social Phobia Scale; SIAS: Social Interaction Anxiety Scale; GSI: Global Severity Index (Brief Symptom Inventory); BDI-II: Beck Depression Inventory-Second Edition; IIP: Inventory of Interpersonal Problems; SF-12 $2_{\mathrm{PH}}$ : Short Form Health Survey physical health subscale; SF-12 $2_{\mathrm{MH}}$ : Short Form Health Survey mental health subscale
} 
prevalence of $12.1 \%$ in western countries (Kessler, et al., 2005). If untreated, SAD typically follows a chronic, unremitting course leading to highly disabling impairments in vocational and social functioning (Fehm, Pelissolo, Furmark, \& Wittchen, 2005; Stein \& Kean, 2000; Yonkers, Dyck, \& Keller, 2001). Although effective treatments such as cognitive behavioral therapy (CBT) are available (Acarturk, Cuijpers, Van Straten, \& de Graaf, 2009; Mayo-Wilson, et al., 2014), far from all individuals suffering from SAD seek and eventually find help. Only about $20-40 \%$ of those with SAD consult a mental health specialist (Gross, et al., 2005). An even lower proportion receives "adequate" treatment defined as antidepressant medication or CBT (Shafran et al., 2009). The low treatment seeking rates are partly due to reasons common to other mental disorders including barriers to treatment seeking such as geographical location, lack of trained therapists, stigma of mental illness, costs of treatment, and lack of awareness about treatment options and effectiveness (Andrade et al., 2014). However, the disorder's specific fear of social situations offers a further explanation for why it takes individuals with SAD up to 20 years to consult a professional (Keller, 2003). For instance, Olfson and colleagues (2000) found that a considerable number of individuals with SAD avoid seeking treatment because of their fear of what others (including the therapist) might think of them. Since socially anxious individuals experience more control and less threat of negative evaluation in online interactions (Lee \& Stapinski, 2012), ICBT may lower the threshold to actively seek help and thus may facilitate treatment seeking especially for SAD patients.

Evidence for the efficacy of guided ICBT for SAD has been provided by at least six independent research groups in Sweden (Andersson, et al., 2006; Andersson, Carlbring, \& Furmark 2012; Carlbring, et al., 2007), Australia (e.g. Titov, Andrews, Schwencke, Drobny, \& Einstein, 2008; Titov, Gibson, Andrews, \& McEvoy, 2009), Switzerland (e.g. 
Berger, et al., 2011; Berger, Hohl, \& Caspar, 2009), Spain (Botella, et al., 2010), Norway (Nordmo et al., 2015) and Romania (Tulbure et al., 2015). In a meta-analysis the overall effect size of ICBT for SAD compared to control conditions was large $(g=0.92,95 \%$ CI 0.74-1.09; Andrews, et al., 2010), and trials directly comparing guided ICBT for SAD with face-to-face therapy revealed that both conditions led to large and similar clinical improvements (Andrews, Davies, \& Titov, 2011; Botella, et al., 2010; Hedman, Andersson, Ljotsson, Andersson, Rück, Mörtberg, et al., 2011). Furthermore, effects tend to be stable over long-term follow-up (e.g. Hedman, Furmark, et al., 2011) and studies examining the effectiveness of ICBT for SAD delivered in regular clinical services show that the effects found in efficacy trials can be replicated in routine clinical practice (Andrews, et al., 2011; Aydos, Titov, \& Andrews, 2009; El Alaoui, et al., 2015; Hedman, Andersson, Ljotsson, Andersson, Rück, \& Lindefors, 2011).

Despite these promising results, there is still room for improving the efficacy of ICBT for SAD since a considerable number of patients do not recover from treatment, a finding which is also reported in studies on face-to-face therapy for SAD (Otto et al., 2000). More specifically, the number of participants fulfilling the criterion of clinically significant change (Jacobson \& Truax, 1991) at the end of treatment ranges between 36$56 \%$ across studies on ICBT for SAD (Boettcher, et al., 2013).

An important line of research on ICBT has focused on the degree of support and guidance required during the self-help treatments in order to be effective. Several metaanalyses show a superiority of guided versus unguided ICBT in terms of efficacy, adherence to treatment and dropout rates (Baumeister, Reichler, Munzinger, \& Lin, 2014; Richards \& Richardson, 2012; Spek, et al., 2007). With regard to SAD, however, good outcomes have also been reported for unguided treatments in trials in which a clinical diagnosis had been established (Berger, Caspar, et al., 2011; Furmark, et al., 
2009; Titov, Andrews, Choi, Schwencke, \& Johnston, 2009). Most of the studies on unguided ICBT for SAD have included integrated moderated or unmoderated discussion forums (Berger, Caspar, et al., 2011; Furmark, et al., 2009; Titov, Andrews, Schwencke, et al., 2009). These forums are usually conceptualized and used as an addition, complementing the main treatment components such as the self-help program and therapist guidance. Whereas previous studies such as Titov (2009) did include access to an open forum, to the best of our knowledge this is the first study that directly compared a web-based treatment with a discussion forum to the same web-based treatment without a discussion forum.

The use of an online discussion forum alone, without self-help guide, does not seem to lead to substantial changes in social anxiety (Andersson, Carlbring, \& Furmark, 2012). However, there is some initial evidence across studies that additional peer support might increase the benefits of internet treatments for SAD. For instance, Furmark et al. (2009) found comparable effects for an internet-based guided self-help treatment for SAD and the same self-help guide delivered as bibliotherapy with no therapist support but with access to an online discussion forum. Furthermore, Titov and colleagues (2009) could increase the effects of unguided ICBT for SAD by adding a clinician-moderated online discussion forum.

One of the experiences with such integrated discussion forums is that many participants value the possibility to share information and experiences with other participants as a helpful element of the treatment package (Berger \& Caspar, 2008). A qualitative analysis of the content of the discussions in the integrated forums showed that therapeutic mechanisms of change may come into play that are known from research on group psychotherapies (e.g. normalization, altruism, instillation of hope, interpersonal learning, imitative behaviour, cohesiveness; Berger, 2011). However, 
there are also problems related to the use of discussion forums in internet-based treatments. A practical problem is that participants usually do not start at the exact same time with such treatments, they are therefore at different points in the treatment and may have different issues to discuss. Another problem concerns the amount of participant contributions in the discussion forums. While usually almost all participants read the messages in the discussion forums, less than half of them also post messages (Berger, Caspar, et al., 2011). Reasons for not actively participating are the optional nature of the forums and, as indicated by participants, the fact that they do not want to write to a large group of anonymous users (Berger, Caspar, et al., 2011).

In the current study, the aforementioned problems with integrated discussion forums were addressed in a clinician-guided group format in which small groups of six participants started together, introduced themselves to each other, and then conjointly worked their way through the internet-based self-help guide. Participants were encouraged to share and discuss their experiences with the other group members and a therapist in an integrated discussion forum. Additionally, they had the opportunity to share their diary entries (e.g. negative thoughts diary) with the rest of the group and to comment on them (see below). Thus, both active conditions used the same material and had some form of support, the difference being that participants in the first condition were supported individually by a clinician, and participants in the second condition were supported by a clinician-guided discussion group.

It should be noted that the internet-based group treatment format is different from group therapy in face-to-face settings, as the main component of the treatment is still the self-help material. However, the internet-based group setting may have advantages compared to the face-to-face group setting. There is evidence suggesting that the face-to-face group situation may be too threatening for some people suffering 
from SAD, resulting in individuals inverting and gaining less in group than in individual settings (Stangier, Heidenreich, Peitz, Lauterbach, \& Clark, 2003). In the internet-based setting, the asynchronous communication with other group members may not provoke overwhelming anxiety symptoms and may allow participants to concentrate on the content of the treatment while still benefiting from the contributions of the other participants.

To our knowledge, the current trial is the first to compare a web-based treatment including a discussion forum to the same treatment without a discussion forum. It is also the first trial to investigate a web-based group treatment. The primary aim of the current study was to evaluate whether a clinician-guided group treatment for SAD was effective in reducing social phobic symptoms when compared to a wait-list control group and a clinician-guided individual treatment (Berger, Caspar, et al., 2011; Berger, et al., 2009). We hypothesized that both active treatment conditions would be superior to the wait-list control condition. With regard to the comparison of the two active treatments, we did not have a clear hypothesis, as no previous study has investigated an internet-based group format. 


\section{Method}

\section{Recruitment and Selection of Participants}

Participants were recruited in Switzerland, Austria and Germany through a study website and postings in internet forums. Several participants found our study homepage via search engines or links from other websites. After registration on the study website, individuals automatically received an email with detailed information on the study and an informed consent form. Those who returned the signed consent form either via mail or email were asked to complete questionnaires and to provide demographic information online.

The first step of the screening process was the administration of the two social phobia measures Social Phobia Scale and Social Interaction Anxiety Scale (SPS and SIAS; German versions: Mattick and Clarke, 1998). Participants who exceeded the predefined cut-off for one of the scales (SPS > 22; SIAS > 33) were interviewed by phone using the Structured Clinical Interview for DSM-IV - Axis I disorders (First, Spitzer, Gibbon, and Williams, 1995; German version: Wittchen, Zaudig, and Fydrich, 1997). Three advanced master students in clinical psychology and the first author conducted the interviews. All of the assessors had been trained in using SCID-I in a workshop including test interviews and detailed feedback and were supervised by the last author. Conducting the SCID in a telephone assessment format was proven to be reliable, with an excellent agreement between the phone and the face-to-face format (Rohde, Lewinsohn, \& Seeley, 1997).

From November 2013 until January 2015, a total of 667 individuals applied to participate via our homepage, and 204 provided written informed consent. Inclusion criteria were (a) being at least 18 years old, (b) having access to a computer with internet connection, (c) having sufficient German language skills, (d) exceeding the cut- 
off scores on the SIAS or SPS, (e) meeting the diagnostic criteria for SAD according to the diagnostic phone interview, and (f) agreeing not to undergo any other form of psychological treatment for the duration of the study. We excluded individuals with active suicidal plans (suicide item on the BDI-II $>1$ or suicidal according to the diagnostic telephone interview), or a history of psychotic or bipolar disorders. These individuals were referred to a local psychiatrist or psychotherapist. Prescribed medication for anxiety or depression only lead to exclusion if the dosage had been changed during the last month prior to participation. Persons who were excluded were given access to the program outside of the study and/or were advised on more suitable treatment options.

Out of the 204 individuals who signed informed consent and filled out the questionnaires, 22 did not exceed the cut-off scores on the SPS or SIAS, 13 were already in psychological treatment, and five could not be reached for the SCID interview (see participant flow in Fig. 1). Out of the 164 people who were interviewed by telephone, 15 had to be excluded because they did not fulfil the diagnostic criteria for SAD according to the SCID-I $(n=9)$, had recently changed the dosage of psychotropic medication $(n=4)$ or reported suicidal ideation and were referred to a local psychiatrist $(n=2)$.

A total of 149 individuals met all inclusion and none of the exclusion criteria and were randomized to one of the three groups. There were $47 \%(n=70)$ men and $53 \%(n$ $=79)$ women. The mean age was 35.38 years $(S D=11.16$; range $=18-76)$. More than half (56.4\%) had been in therapy for psychological problems in the past (see Table 2 for more demographic information).

Of the 149 persons, 72 (48.3\%) fulfilled the criteria of at least one other disorder in addition to SAD: 47 (31.5\%) individuals were diagnosed with one comorbid disorder, $22(14.8 \%)$ with two additional disorders and $3(2 \%)$ fulfilled the criteria of three 
comorbid disorders. The most common comorbid disorders in the sample were affective and other anxiety disorders: Forty-three persons (28.8\%) suffered from depression and/or dysthymia, 24 (16.1\%) from specific phobias and 11 (7.4\%) individuals fulfilled the diagnostic criteria for generalized anxiety disorder.

\section{INSERT FIGURE 1 ABOUT HERE.}

\section{Outcome Measures}

Social anxiety. The main outcome measures were the Social Phobia Scale and the Social Interaction Anxiety Scale (SPS, SIAS; Mattick and Clarke, 1998; German versions: Stangier, Heidenreich, Berardi, Golbs, and Hoyer, 1999). These self-report measures assess fears of being judged by others during daily activities (SPS) and more general fears in social interaction (SIAS), respectively. Each scale consists of 20 items to be rated on a 5-point Likert scale, resulting in a total score ranging from 0 to 80 . As some of the most commonly used measures for SAD, the SPS and SIAS have been found to be valid, reliable and useful for clinical and research purposes (Stangier, et al., 1999). Administered online, the SPS and SIAS have shown the same robust psychometric properties as the pen-and-paper version (Hedman, et al., 2010). We also report any worsening on the primary outcome measures SPS and SIAS as a measure of negative effects.

Depressive symptoms. To account for the high comorbidity of social phobia and depression, clients were asked to complete the German version of the Beck Depression Inventory-II (BDI-II; Hautzinger, Keller, \& Kühner, 2006). The BDI-II is one of the most widely used self-report measures to assess depression in research in clinical practice. It consists of 21 items to be rated on a scale from 0 to 3 and has shown robust psychometric properties for internet delivery with SAD clients (Hedman, et al., 2010).

Psychiatric symptoms. As a measurement of psychiatric symptoms, participants 
completed the German version of the Brief Symptom Inventory (BSI; Derogatis, 1993; German version: Franke, 2000). The BSI assesses psychological distress on nine dimensions such as anxiety, insecurity in social situations, depressiveness and compulsivity. The participants are asked to rate the occurrence of symptoms within the last week on a 5-point Likert scale from 0 to 4 . In this study, we report the Global Severity Index (GSI), which is a mean score over all items. As an economic instrument with robust psychometric properties, the BSI is commonly administered to detect prepost changes (Franke, 2000).

Interpersonal problems. The Inventory of Interpersonal Problems (IIP) was used to assess interpersonal distress (Horowitz, Strauss, \& Kordy, 2000). The IIP has shown adequate psychometric properties (Horowitz, Rosenberg, Baer, Ureno, \& Villasenor, 1988). It consists of 64 items that are answered on a 5-point Likert scale from 0 to 4 . We report mean scores over all items as a measure of interpersonal distress.

Mental and physical health. The SF-12 Health Survey (Gandek, et al., 1998) is a condensed version of the Short Form Health Survey (SF-36) measuring physical and mental health on two subscales (physical health subscale: SF-12PH; mental health subscale: SF-12мн). Participants were asked to report the presence and severity of physical and mental problems over the course of the last 4 weeks. Its 12 items cover pain, psychological problems, as well as impairments in everyday functioning. Because of its good retest reliability and brevity, the SF-12 is widely used as an estimate of general quality of life (Gandek, et al., 1998).

Client satisfaction. At post-treatment, a measure of global patient satisfaction was administered (Client Satisfaction Questionnaire, CSQ-8; Attkisson and Zwick, 1982; German version, ZUF-8: Schmidt, Lamprecht, and Wittmann, 1989).

Adherence to treatment and completion rates. To investigate adherence to 
treatment and completion rates we assessed the number of lessons completed, time spent in the self-help program and usage of the different types of support. We measured the number of completed exercises by counting the number of entries in the corresponding diaries. The time spent in the program was investigated by using login data. Because participants could have potentially been logged in while not working with the program, usage time windows with no activity in the program for more than $15 \mathrm{~min}$ were not counted. The guiding psychologists recorded the weekly therapist time individually for each participant in the IT condition and per group in the GT condition. To ensure comparability, therapist time per group in the GT condition was divided by six, resulting in an estimate of required therapist time per week and participant.

\section{Interventions}

All participants accessed the same self-help material for SAD. The material is based on the established cognitive-behavioural model by Clark and Wells (1995) and has been proven efficacious in previous studies (Berger, Caspar, et al., 2011; Berger, et al., 2009; Berger, Hohl, \& Caspar, 2010; Boettcher, Berger, \& Renneberg, 2012). The program contains eight text-based sessions to be completed in a sequential order. Table 1 shows the contents of the eight text-based modules of the self-help material (for a more detailed description see Berger, Caspar, et al., 2011; Berger, et al., 2009). In each session, different diaries and exercises are introduced (such as a diary of fear inducing situations and a diary of negative thoughts). Each session takes approximately 50 minutes to complete. Participants were encouraged to work through one session per week and repeat the exercises as often as possible during the 12 weeks of treatment.

\section{INSERT TABLE 1 ABOUT HERE.}

Clinician-guided individual treatment (IT). The participants in this condition worked with the self-help material described above. Additionally, a therapist monitored 
their progress in the program and contacted the participants via email on a weekly basis to provide feedback and structure. The participants could use the integrated message function to contact their therapist whenever they felt the need to and were informed that the therapist would answer within three working days. The main aim of the therapist's messages was to reinforce the independent program use and keep up the participant's motivation. When a participant was inactive for a week, the therapist offered assistance with the task at hand.

Clinician-guided group treatment (GT). Participants in the second active condition used the same self-help material as the first condition but had additional access to a clinician-guided discussion forum. Each group consisted of six members who started the treatment at the same time. Participants were consecutively allocated to groups without randomization to minimize waiting times. The discussion began with the therapist introducing herself and explaining some guidelines about the forum. In order to ensure anonymity, the group members were asked to introduce themselves only by giving information on the nature and duration of their symptoms. For all communication, the participants were instructed to only use a pseudonym. The supporting psychologists supervised adherence to these guidelines and deleted any information posted in the forum that could identify participants (e.g. city names). This happened twice during the trial. All messages in the forum by the therapist or the group members were available to everyone in the group. The therapist encouraged the participants to share their experiences, problems and questions with one another. Group members also had the opportunity to make their diary entries available to the rest of the group and comment on others' contributions. In addition, participants had the opportunity to see what modules and exercises the other group members were currently working on. Analogous to the first treatment condition, the psychologist 
contacted the group on a weekly basis by opening a new thread in the forum, addressing the current module's topic and giving feedback on the group's progress (e.g. “This week's topic has been dealing with negative thoughts. I have seen that all of you have started working with the thought diary. How did that work for you?"). Just like in the individual guidance condition, the therapists' messages were aimed at providing structure and motivation. In both treatment groups, we used SSL (Secure Sockets Layer) encryption to secure all communication.

Wait-list control condition (WL). After a 12-week delay, individuals in the waitlist control condition received access to the self-help material with individual clinician guidance (equal to condition 1).

Clinicians. The clinicians were one female psychologist with a Master's degree in clinical psychology in her first year of a post-graduate CBT training program and three female Master of Science students who were in their last term of a graduate program in clinical psychology and psychotherapy. All clinicians were supervised by the last author (TB) and received support regarding email correspondence when needed. Participants were consecutively allocated to clinicians without randomization in order to minimize waiting times.

\section{Procedure}

After meeting the inclusion and none of the exclusion criteria, participants were assigned to one of the three conditions. Weighted randomization $(2: 2: 1)$ was used resulting in 60 participants in each of the active conditions and 29 in the wait-list control condition. The allocation list was made using a computerized random number generator and was concealed from the investigators and participants. After the randomization, the participants received an email regarding their allocation. 
In the group-guided condition, the participants could start as soon as a group of six was randomized to this treatment, which meant that there was a short waiting period, similar to the beginning of a face-to-face group treatment. In the individual treatment condition, the participants received the necessary information to start with the program 10 days after randomization in order to facilitate comparisons to the group-guided condition.

All participants in the active conditions were advised to work through one session per week and to start a new session after receiving a weekly feedback by the clinician. At the end of each session, there was a summary of the tasks to be completed in the following week. The next session was only made available if the users indicated that they understood the content and agreed to do the exercises (for example practicing a certain relaxation technique). After 12 weeks, all participants were asked to fill out the post-assessment questionnaires online and to participate in a second telephone interview to re-evaluate their diagnostic status. The assessors could not be kept blind regarding group allocation because some participants revealed information about the treatment during the interview. Six months after the beginning of treatment, participants were contacted via email and asked to fill out the questionnaires again. The protocol of this study was approved by the Ethics Committee of the Canton of Bern and written consent was obtained from all participants. The trial was prospectively registered with controlled-trials.com (ISRCTN75894275) and a study protocol has been published (Schulz, Stolz, \& Berger, 2014). Participation in the study was free of charge and no reimbursement was given to participants.

\section{Power Calculation}

Regarding differences between the two active conditions, we wanted to be able to demonstrate standardized effect sizes (Cohen's $d$ ) of 0.35 . Smaller effects were 
considered clinically non-relevant. At an $\alpha$-error level of 0.05 , a statistical power (1Beta) of 0.80 , and a correlation between pre- and post-measurements found in our previous studies, 60 participants were needed in each of the two active conditions. Based on earlier findings we expected large differences between the active conditions and the wait-list control. A priori power analysis showed that a sample size of 30 in the wait-list control would be sufficient to show effect sizes of this magnitude.

\section{Statistical Analysis}

Group differences in socio-demographic data and other measures at pretreatment were tested with analyses of variance (ANOVAs) and chi-square tests where variables consisted of nominal data. All analyses were based on the intention-to-treat sample.

To determine differences in the primary and secondary outcome variables, a mixed-effects models approach was used (Gueorguieva \& Krystal, 2004). These models use all available data on a subject and estimate parameters about missing values. Furthermore, mixed-effects models can account for the correlation of the repeated measurements on the same subjects (pre, post, follow-up). A separate model was estimated for each of the six outcome measures. We tested the goodness of fit for models assuming compound symmetry (CS), unstructured (US) or a heterogeneous autoregressive covariance structure (AR1). In all models, assuming a compound symmetry covariance structure showed the best fit based on the Bayesian Information Criterion (BIC) (SPS: $\mathrm{BIC}_{\mathrm{CS}}=2029.49$ vs. $\mathrm{BIC}_{\mathrm{US}}=2034.56$ vs. $\mathrm{BIC}_{\mathrm{AR} 1}=2034.56$ vs.; $\mathrm{SIAS}$ : $\mathrm{BIC}_{\mathrm{CS}}=2088.49$ vs. $\mathrm{BIC}_{\mathrm{us}}=2093.79$ vs. $\left.\mathrm{BIC}_{\mathrm{AR} 1}=2093.79\right)$. The same pattern was found for all secondary outcome measures. Thus, we report models with a compound symmetry covariance structure applying the restricted likelihood (REML) estimation in all analyses. For post-hoc testing of differences, a Bonferroni correction for multiple 
testing was used. Concerning the diagnostic response rates at post-treatment and follow-up, dropouts were regarded as treatment failures (i.e. still fulfilling the diagnostic criteria of SAD). Differences in diagnostic response rates between the treatment conditions were calculated using chi-square tests.

Within- and between-groups effect sizes (Cohen's $d$ ) were calculated based on estimated means and the pooled standard deviation from the observed means. Differences between the treatment groups concerning client satisfaction were calculated using $t$-tests. To evaluate possible predictors of outcome, we calculated residual gain scores (RGSs) separately for the SPS and SIAS to quantify symptom change. To compute residual gain, raw scores of the outcome measures were first converted to $Z$ scores. Change was then calculated by subtracting the pre-treatment score, which was multiplied by the correlation between scores at pre-treatment and post-treatment, from the post-treatment score (RGS $=Z_{2}-Z_{1} r_{12}$; Steketee and Chambless, 1992). We then inverted the RGSs so that a positive value indicates symptom reduction. RGSs control for initial differences as well as for measurement error caused by repeated assessment with the same instrument and are particularly useful for investigating correlations with change (Beutler \& Hamblin, 1986).

To identify negative treatment effects, we first report any worsening as defined by absolute change in SPS and SIAS, and then deterioration according to the Reliable Change Index (RCI; Jacobson \& Truax, 1991). In this sample, a reliable deterioration meant a change of 7 points on the SPS or 11 points on the SIAS. A priori power calculations were conducted using G*Power (Faul, Erdfelder, Lang, \& Buchner, 2007). All of the other analyses were performed in SPSS version 23. 


\section{Results}

\section{Pre-Treatment Evaluation}

Groups did not differ significantly with regard to age, $F(2,146)=0.77, p=.46$, or other descriptive characteristics, $\chi^{2}(2-8)=0.40-9.08, p>.24$ (see Table 2 ). There were no significant pre-treatment differences between study groups on primary social anxiety measures $F(2,146)=0.02-.24, p>.79$ or on secondary measures, $F(2,146)=0.06-.98, p$ $>$.29). In comparison to a German norm population, the pre-treatment scores on the SPS and SIAS in the current sample were approximately three standard deviations higher (Lincoln, et al., 2003) and about one standard deviation higher than in a sample comparing face-to-face group with individual treatment (Stangier, Heidenreich, Peitz, Lauterbach, \& Clark, 2003). Social phobic symptoms at baseline were slightly elevated in comparison to other studies investigating ICBT for SAD (Berger, Caspar, et al., 2011;

Hedman, Furmark, et al., 2011; Titov, Andrews, Choi, Schwencke, \& Mahoney, 2008).

\section{Dropout Analysis}

In total, 34 (25\%) participants dropped out before the post-treatment assessment (14 in the individual guidance condition, 15 in the group guidance condition and 5 in the wait-list control group). Four participants in each of the active conditions and two in the wait-list control wrote to their clinician that they would like to seek faceto-face treatment as they felt it would be more helpful for them (four of them indicated that they needed help for another disorder than SAD, e.g., depression). We helped them find an appropriate treatment. Interestingly, four of those individuals wished to continue with the program, but together with a clinician in a blended treatment setting. Four participants (three in the IT condition, one in the GT condition) dropped out because they started with another treatment. Other reasons for dropping out were spontaneous remission after the first telephone interview (one person in the group 
condition), finding the program/questionnaires too exhausting or too time consuming (two in the individual condition, one in the group condition), disappointment by the assignment (one in the group condition, two in the wait-list control group) or physical problems (one in the group condition). As for the remaining dropouts ( $n=12 ; 5$ in the IT condition, 6 in the GT condition, 1 in the WL), reasons remain largely unclear because they could not be reached (e.g. because the email address with which they signed up was inactive).

When looking at the trajectory of cases with missing post-treatment data, there were four peaks in attrition or moments of increased probability for early termination: $11.8 \%$ did not start the treatment, $14.7 \%$ of dropouts only completed the first module, $26.5 \%$ terminated treatment after the fifth module (introduction to exposure exercises) and $17.6 \%$ completed all of the eight modules. Between post- and follow-up assessment, an additional 37 participants dropped out (14 in the individual treatment condition, 13 in the group treatment condition, and 10 in the wait-list control group). Thus, 78 participants (52.35\%) provided self-report data at follow-up and 52 of those could be reached for the last clinical interview. Reasons for dropping out between post-treatment and follow-up remained unknown since none of them could be reached.

No significant differences were observed regarding the dropout rates in the three conditions at post-treatment, $\chi^{2}(2)=0.68, p=.71$, or at follow-up, $\chi^{2}(2)=0.39, p=.98$. There were no significant differences in terms of demographics, $\chi^{2}(1-5)=0.89-5.96$, all ps $>.06$, pre-treatment, or post-treatment scores between those who provided posttreatment and follow-up data and those who did not, $t(147)=0.01-5.78$, all $p s>.12$, with one exception: There was a significant difference between those who provided data at post-treatment and those who did not regarding the pre-treatment SPS scores, $t(147)$ 
$=2.99, p=.003$, indicating that cases with missing post-treatment data had an increased SPS score at pre-treatment.

\section{INSERT TABLE 2 ABOUT HERE.}

\section{Overall Effects at Post-Treatment}

Observed means, estimated means, and standard deviations for all self-report measures at pre- and post-treatment are presented in Table 3. A mixed models analysis of the primary outcome measures SPS $\left(F_{2,122.45}=15.17, p<.001\right)$ and SIAS $\left(F_{2,119.92}=\right.$ $8.10, p=.001$ ) revealed highly significant group by time interactions. Similar results were observed for the secondary outcome measures GSI $\left(F_{2,118.36}=6.15, p=.003\right)$, BDI-II $\left(\mathrm{F}_{2,119.86}=3.60, p=.03\right), \operatorname{IIP}\left(F_{2,122.97}=8.14, p=.00\right)$, and the psychological subscale of the SF12 $\left(F_{2,122.24}=3.66, p=.029\right)$. No significant interaction was found for the physical subscale of the SF-12 $\left(F_{2,122.70}=0.22, p=.80\right)$.

Bonferroni-corrected post-hoc tests for pairwise comparisons indicated that participants in the active conditions improved significantly more than participants in the wait-list control group on the main outcome measures SIAS and SPS (all $p s<.007$, see Table 3). The active conditions did not differ regarding the SPS and SIAS (all $p$ s > .63). Compared to the wait-list, both active conditions showed only marginally significant improvements on most of the secondary outcome measures, again with the exception of the physical subscale of the SF-12. None of the comparisons between the two active conditions were significant on any of the secondary measures (all $p s>.31$ ).

\section{INSERT TABLE 3 ABOUT HERE.}

\section{Effect Sizes at Post-Treatment}

Effect sizes (Cohen's $d$ ) were calculated both within and between groups from estimated means and observed pooled standard deviations, and are presented in Table 4. At post-treatment, the within-group effect sizes of the active conditions for the SPS 
were $d=1.50$ (IT; 95\% CI: $1.10-1.91$ ) and $d=1.03$ (GT; CI: 0.65-1.41). For the SIAS, effect sizes were $d=1.08$ (IT; CI: 0.70-1.47) and $d=0.95$ (GT; CI: 0.57-1.33). Withingroup effect sizes for the secondary outcome measures in the individual treatment condition were GSI: $d=0.94$ (CI: 0.56-1.31), BDI-II: $d=0.88$ (CI: 0.50-1.25), IIP: $d=0.86$ (CI: 0.48-1.23), SF-12 physical subscale: $d=-0.12$, (CI: $-0.47-0.24)$; and SF-12 mental health subscale: $d=0.90$ (CI: 0.53-1.28). Accordingly, pre-post effect sizes in the group treatment condition were GSI: $d=0.90$ (CI: 0.52-1.27), BDI-II: $d=0.78$ (CI: 0.41-1.16), IIP: $d=0.69$ (CI: 0.32-1.06), SF-12 physical health subscale: $d=-0.02$, (CI: $-0.38-0.34)$; and SF-12 mental health subscale: $d=0.89$ (CI: 0.51-1.26). In contrast, the within-group effect sizes for the wait-list control group were small to negligible, ranging from $d=0.14$ (CI: $-0.38-0.65)$ on the SPS to 0.28 (CI: $-0.23-0.80)$ on the SIAS, and between $d=0.00$ (IIP; CI: $-0.52-0.52$ ) to $d=0.31$ (SF-12 mental health subscale; CI: $-0.21-0.83$ ) on secondary outcomes. Comparisons between each of the active conditions and the waitlist control group revealed large effects on the primary outcome measures in favour of the active treatments (SPS: $d_{\mathrm{IT}}=1.22, d_{\mathrm{GT}}=0.84$; SIAS: $d_{\mathrm{IT}}=0.94, d_{\mathrm{GT}}=0.84$ ). The effect sizes of the secondary measures ranged between $d=0.15(\mathrm{SF}-12 \mathrm{PH})$ and $d=0.53(\mathrm{GSI})$ for the comparison of individual treatment and the wait-list, and between $d=0.19$ (SF$12 \mathrm{PH}$ ) and $d=0.56$ (IIP) for the comparison of group treatment and the wait-list. Between-group effect sizes comparing the active conditions were close to zero or small, with a tendency in favour of the individual treatment group on the primary outcome measures (SPS: $d=0.26, \mathrm{CI}:-0.10-0.63$; SIAS: $d=0.12, \mathrm{CI}:-0.24-0.48)$. On the secondary outcome measures, between-group effect sizes comparing the active conditions varied between $d=-0.02$ (CI: $-0.38-0.34$ in favour of the GT condition) on the GSI and $d=0.34$ (CI: $-0.02-0.70$ in favour of the IT condition) on the SF-12 physical subscale. 
INSERT TABLE 4 ABOUT HERE.

\section{Diagnostic Status at Post-Treatment}

Concerning the diagnostic response rates at post-treatment and follow-up, dropouts were regarded as treatment failures. Thus, according to the clinical interview at post-treatment, 15 out of 60 individuals (25\%) in each of the active treatment conditions no longer met the criteria for SAD. In contrast, no participant in the wait-list could be considered remitted after 12 weeks. The overall difference in response rates reached statistical significance $\left(\chi^{2}(2)=13.11, p<.001\right)$. Pairwise comparisons revealed that both the individual $\left(\chi^{2}(1)=12.62, p<.001\right)$ and the group treatment condition $\left(\chi^{2}(1)=13.41, p<.001\right)$ significantly differed from the wait-list condition .

\section{Treatment Effects at Six-Month Follow-Up}

At six-month follow-up, the wait-list control group had received access to the self-help guide with individual guidance and comparisons could only be made between the clinician-guided individual treatment and the clinician-guided group treatment. Mixed-models analyses including pre, post and follow-up scores showed significant time effects for the primary outcome measures SPS $\left(\mathrm{F}_{2,162.96}=120.59, p<.001\right)$ and SIAS $\left(F_{2,164.32}=91.12, p<.001\right)$, as well as for the secondary outcome measures BDI-II $\left(\mathrm{F}_{2,163.07}=163.07, p<.001\right), \mathrm{GSI}\left(\mathrm{F}_{2,160.82}=64.37, p<.001\right), \operatorname{IIP}\left(\mathrm{F}_{2,168.14}=53.25, p<.001\right)$ and the psychological subscale of the SF-12 $\left(\mathrm{F}_{2,164.57}=44.31, p<.001\right)$. However, there was no significant time effect for the physical subscale of the SF-12 $\left(\mathrm{F}_{2,159.52}=1.03, p=\right.$ .36).

Importantly, no group by time interactions or significant group effects were observed (all $p s>.29$ ), indicating that both active groups benefitted equally from the treatment until the follow-up assessment. As indicated in Table 4, pre-to-follow-up within-group effect sizes were large for the main outcome measures $(d s>1.07)$ and 
moderate to large for secondary outcome measures $(d s>0.56)$, except for the physical subscale of the SF-12 $\left(d_{\mathrm{IT}}=-0.12 ; d_{\mathrm{GT}}-0.18\right)$.

Bonferroni-corrected pairwise comparisons indicated that participants in both groups showed highly significant improvements from pre-treatment to follow-up assessment on all measures (all $p s<.001$ ), again with the exception of the SF-12 physical subscale (IT: $p=.99 ; \mathrm{GT}: p=.85$ ). No significant improvement or deterioration was observed from post-treatment to follow-up on any of the measures (all $p s>.63$ ). According to the last clinical interview, 14/60 patients in the individual treatment condition and 14/60 in the group treatment condition no longer met the criteria for SAD at follow-up.

\section{Negative Effects}

At post-treatment, 11 out of 91 treatment completers $(12.1 \%)$ showed deteriorated scores (as in any negative change) on the SPS (IT: $n=4$, GT: $n=7$ ) or SIAS (IT: $n=6$, GT: $n=5$ ). The average deterioration of those with worsened scores was $M=$ 4.36 on the SPS and $M=5.27$ on the SIAS. According to the reliable change index (Jacobson \& Truax, 1991), two participants (both in the group treatment condition) deteriorated reliably on the SPS and one participant (also in the group treatment condition) showed a reliably worsened score on the SIAS.

At follow-up, five out of 63 completers (7.9\%; IT: 3/32; GT: 2/31) showed a deteriorated absolute SPS score and six out of 63 (9.5\%, IT: 3/32; GT: 3/31) had a deteriorated absolute SIAS score compared to pre-treatment. None of them were reliably deteriorated according to the RCI. Treatment groups did not differ significantly regarding deterioration rates on any of the primary outcome measures at posttreatment (SPS: $\chi^{2}(1)=1.01, p=.32 ;$ SIAS: $\left.\chi^{2}(1)=0.80, p=.77\right)$ or follow-up (SPS: $\chi^{2}(1)$ $=0.22, p=.64 ;$ SIAS: $\left.\chi^{2}(1)=0.002, p=.97\right)$. 


\section{Client Satisfaction}

Overall, participants indicated a high level of satisfaction with the treatment. The mean score on the CSQ-8 was at $3.23(S D=0.56)$, which translates to being "somewhat" (3) to "very satisfied" (4). The mean score was slightly higher in the individual treatment condition (IT: $M=3.33, S D=0.54 ; \mathrm{GT}: M=3.12, S D=0.60$ ), yet the difference failed to reach statistical significance, $t(89)=1.82, p=.07, d=0.38$.

\section{Program Usage}

Lessons completed. On average, participants completed 6.32 of the eight lessons $(S D=2.16)$. The mean number of completed lessons in the individual treatment condition was $6.52(S D=2.10)$ and $6.35(S D=2.20)$ in the group treatment condition. Treatment groups did not differ significantly, $t(118)=0.43, p=.67, d=0.09$. Thirty-five participants (58.33\%) in the IT condition and 34 participants in the GT condition (56.67\%) completed all eight modules.

Time spent in the program. Participants in the active conditions spent an average of 15 hours and 39 minutes in the program, ranging from 5 minutes to 67 hours. No significant difference was found between the individual and group-guided condition, $t(118)=0.8, p=.43$. The average time spent logged on was 16 hours and 33 minutes for the individual treatment condition $(S D=12$ hours 56 minutes; $M d n=13$ hours 7 minutes) and 14 hours and 44 minutes in the group treatment condition (SD = 11 hours 59 minutes; $M d n=12$ hours 4 minutes).

Exercises completed. On average, participants conducted $14.5(S D=20.12$; range: $=0$ - 169) relaxation exercises, and recorded 11 anxiety-provoking situations (SD $=12.36 ;$ range $=0-73)$. They questioned 6.6 negative beliefs $(S D=9.21 ;$ range $=0-55)$ and noted an average of 8.1 exposures exercises $(S D=9.20$; range $=0-403)$. Significant group differences between the two active conditions were found regarding the number 
of entries in the thought diary, $t(77.63)=3.05, p=.003$ (IT: $M=9.08, S D=11.67$, GT: $M=$ 4.13, $S D=4.70, d=0.64)$ and the number of anxiety-provoking situations, $t(81.68)=$ 3.16, $p=.002$, (IT: $M=14.45, S D=15.40 ; \mathrm{GT}: M=7.58 ; S D=6.88, d=0.66$ ), indicating that participants in the individual treatment condition used the diaries more often than participants in the group format condition.

\section{Use of Contact Modalities}

Individual treatment condition: Contact with clinician. On average, participants in the individually guided condition wrote $6.68(S D=4.27)$ messages to their clinicians, with an overall average number of 1004 words $(S D=127.5)$. To compose these messages, individually guided participants spent 1 hour and 51 minutes in the contact section. Clinicians spent an average of 17 minutes per week and participant monitoring treatment progress and writing messages.

Group treatment condition: Use of participative-collaborative elements. On average, participants spent 2 hours and 40 minutes writing and reading messages in the forum. Their guiding clinicians invested an average of 4.47 minutes per week and participant moderating the discussion. $93.33 \%$ of the users $(56 / 60)$ wrote at least one message in the forum $(M=4.68, S D=5.86$, range: $0-40)$.

\section{Predictors of Outcome}

To explore potential predictors of outcome, we calculated the residual gain score for the primary outcome measures SPS and SIAS. None of the pre-treatment variables such as age, gender, education level, previous treatment, medication status, or number of comorbid disorders were significantly related to the primary outcome measures in any of the active conditions (all $p s>.21$ ).

In the individual treatment condition, measures of program use were positively associated with symptom reduction; number of entries in the anxiety diary (rhosps $=.33$, 
$p=.026 ;$ rhosias $=.34, p=.020$ ), number of challenged negative thoughts (rhosps $=.37, p$ $=.012$; rhosias $=.31, p=.033)$, number of exposures exercises (rhosps $=.41, p=.004$; rhosias $=.33, p=0.026)$, and total time spent in the program $(\operatorname{rhosps}=.37, p=.011$; rhosias $=.31, p=0.039$ ). In contrast, we only observed one significant association in the group treatment condition (number of entries in the exposure diary: rhosps $=.33, p=$ .027). None of the other potential predictors were associated with symptom reduction (number of entries in the anxiety diary: rhosias $=.16 p=.30$; number of challenged negative thoughts: rhosPS $=.08, p=.59 ;$ rhosiAs $=.05, p=.73$; number of exposures exercises: rhosPs $=.29, p=.07 ;$ rhosias $=.26, p=.08$ ). 


\section{Discussion}

The aim of this study was to investigate whether a newly developed clinicianguided group ICBT was beneficial for patients suffering from SAD when compared to a wait-list control group, and how the efficacy of this novel treatment format compares to a clinician-guided individual ICBT evaluated in previous trials (e.g. Berger, Caspar, et al., 2011). Overall, results suggest that SAD can be successfully treated with a clinicianguided group ICBT . We found significant treatment effects on social anxiety symptom severity, depressive symptoms, interpersonal problems, general symptom severity and psychological wellbeing immediately after the treatment and significant time effects at a six-month follow-up indicating that treatment gains could be maintained by most of the participants. Post-hoc comparisons at post-treatment showed that participants using the program in the novel group format improved significantly more regarding social anxiety symptoms than participants in the wait-list control group. There was no significant difference between the two active treatment arms regarding social phobic symptom reduction. In comparison to a previous study in which only half of the participants posted messages in a forum (Berger, Caspar, et al., 2011), the participation in the online discussion in the group treatment condition of this trial was high, with 56 of 60 participants contributing to the discussion. It appears that a more structured and clinician-guided approach to the group format may be superior to an open, unmoderated group with regard to participation in online discussions.

Additionally, the high ratings of client satisfaction and the usage data of the forum indicate that the group-guided format was well received. In fact, some participants revealed in the diagnostic interview that they specifically signed up for the study in hopes of being assigned to this condition. Future research is needed to 
determine the influence of individual patient preferences regarding the type of guidance on treatment outcome.

The large effect sizes on the main outcome measures at post-treatment and follow-up are equivalent to those found in previous studies using the same self-help material (Berger, Caspar, et al., 2011; Berger, et al., 2010) and other internet-based interventions for SAD (e.g. Hedman, Andersson, Ljotsson, Andersson, Rück, Mörtberg, et al., 2011; Titov, Andrews, Choi, et al., 2008). Regarding the diagnostic response rate, the proportion of participants who did not fulfil the diagnostic criteria of SAD at posttreatment anymore was similar to that observed in other studies on ICBT for SAD (Hedman, Andersson, Ljotsson, Andersson, Rück, Mörtberg, et al., 2011; Titov, Andrews, Choi, et al., 2008) and to those found by Otto and colleagues (2000) in pharmacological and face-to-face group treatments. However, there are other studies on ICBT for SAD that observed higher recovery rates (e.g. Tulbure et al., 2015). The comparatively lower rate in this trial might partly be due to the high number of missings (possible reasons for this are discussed below) and the fact that we regarded participants who did not provide post-treatment data as non-responders. With the relatively high dropout rate, this may have resulted in a too conservative estimate of diagnostic response.

It should be noted that the baseline impairment caused by social anxiety symptoms in the present sample was comparatively high. For example, the SPS pretreatment score was about one standard deviation, and the SIAS pre-treatment score about half a standard deviation higher than in a study investigating the effectiveness of a face-to-face group and individual treatment (Stangier, et al., 2003) and another recent study on ICBT (El Alaoui, et al., 2015). The high initial symptom severity in the current sample might also explain the fact that we observed large effect sizes, while a considerable number of participants still met the criteria for SAD after the treatment. 
In the present study, no significant differences were found between the group treatment and the individual treatment format regarding the improvement of social phobia symptoms and diagnostic response or attrition rates. There was, however, a significant difference in the amount of time the supporting clinicians invested in the guidance: On average, an individually guided patient required three times more clinician time than a patient using the group format. Taking into consideration that in routine care more therapist time equals higher costs, it can be assumed that a group format has the potential to be more cost effective, while being equally beneficial to the patients.

Further, we only found marginally significant post-hoc differences between the wait-list control group and the active conditions on the secondary outcome measures, indicating that the intervention mainly targeted the social phobic symptoms. This is incongruous with previous research (Berger, Caspar, et al., 2011; Titov, Gibson, et al., 2009). Considering that we observed moderate between-group effects for comparisons with the wait-list and large within-group effect sizes on secondary outcome measures, it seems likely that the study was underpowered to statistically detect this level of effects, especially when using the rather conservative Bonferroni corrections.

Furthermore, the current sample had a notably high comorbidity rate, with 48.3\% suffering from at least one additional disorder (compared to, for example, $12.5 \%$ comorbid psychiatric disorders observed by Andersson, et al., 2006). Twenty-nine percent of the current sample fulfilled the criteria of a comorbid depression and/or dysthymia, which is about twice as high as the rate observed by El Alaoui and colleagues (2015) in an effectiveness study on ICBT for SAD conducted in routine psychiatric care. One the one hand, a high comorbidity rate would imply that participants had the opportunity to improve significantly. On the other hand, one could argue that such a high psychopathological impairment requires a tailored approach, which includes 
specific modules targeting individual comorbid syndromes. This type of tailored treatment was shown to be superior to a standardized treatment among depressed patients with higher comorbidity (Johansson, et al., 2012).

The question of the underlying change mechanisms of ICBT is still largely unresolved (Andersson, Carlbring, Berger, Almlöv, \& Cuijpers, 2009). Some of the research on this topic has focused on usage data or therapeutic guidance as potential factors that influence treatment outcome. Based on diary data, we found that IT participants challenged more negative thoughts and recorded more anxiety provoking situations. Moreover, for the IT group we observed positive associations between measures of program use and symptom reduction, which is consistent with previous research on ICBT (Berger, Caspar, et al., 2011; El Alaoui, et al., 2015). Interestingly, we did not find as many of these associations for patients in the clinician-guided group treatment condition. In the clinician-guided group format, only the amount of entries in the exposure diary was significantly associated with symptom reduction. This finding suggests that it is important to practice skills learnt in ICBT in "real life". On the other hand, and taking into consideration that we found no difference in SAD symptom reduction between the active conditions, this pattern of results might also propose that different mechanisms might have been responsible for the change in the different conditions. It is possible that the mutual exchange and the resulting group processes might partly compensate for the less comprehensive use of the introduced CBT techniques. Of course, this is a tentative conclusion and further research is needed to identify the therapeutic mechanisms of patients' mutual exchange, for example by using qualitative methods to analyse the content of the discussion.

We also found an association between baseline symptom severity on the SPS and risk of dropping out, which is inconsistent with previous research on ICBT (Berger, 
Boettcher, \& Caspar, 2013; Calear, Christensen, Mackinnon, \& Griffiths, 2013) and faceto-face CBT for SAD (Eskildsen, Hougaard, \& Rosenberg, 2010). As for a practical implication, the finding of the current trial suggests that it may be necessary for guiding clinicians to monitor the treatment progress of severely impaired clients more closely in order to prevent patients dropping out. To our knowledge, no study on ICBT for SAD to date has reported similar findings, so further research is needed to clarify the nature of this association and its practical implications.

Dropout analyses revealed, however, that more than one out of four cases with missing post-treatment data dropped out after the fifth module, in which the rationale for the in vivo exposure was introduced. According to client reports after the treatment, the fifth module was the most challenging and it seems probable that some individuals were too anxious or not yet ready to confront anxiety-inducing situations. This would indicate that some patients with SAD need additional support to implement the exposure exercises, for example in form of a more closely knit therapeutic guidance.

This study has several limitations. First, the dropout rate was higher than in previous studies, especially at follow-up. One possible explanation could be that participants were encouraged to create a new email address for all study correspondence in order to ensure anonymity. It appears that some did not check this study-related email account regularly. Thus, some of the emails asking participants to fill out the questionnaires went unanswered or could not be delivered. We tried to counterbalance this loss of data by employing statistical analyses that account for the missings and chose a conservative approach by treating dropouts as non-responders in the analysis of diagnostic status. Yet, high dropout rates remain one of the major obstacles faced by this type of research. The second limitation relates to the generalizability of the results since this study is based on a self-selected sample of 
individuals who expressed their interest in ICBT. It can been argued, however, that results may generally apply to a population that is interested in this kind of treatment delivery (Buntrock, et al., 2015) and data from several effectiveness studies suggest that internet interventions work in routine practice just as well as in research studies (Andersson \& Hedman, 2013). Third, the study had adequate power (.80) to detect small to moderate effect sizes of $d=0.35$ and higher, but was underpowered to detect small effect sizes that would favour one of the active treatment conditions over the other. Fourth, assessors at post-treatment could not be kept blind to group assignment because participants disclosed information on the treatment during the clinical interview. Fifth, it would have been interesting to include a pure self-help treatment arm without any form of guidance. As previous studies have shown that unguided ICBT can be effective (e.g. Berger, Hämmerli, Gubser, Andersson, \& Caspar, 2011; Titov, Andrews, Choi, et al., 2009), we cannot rule out the possibility that the effects observed in this trial were caused by using the self-help material alone, regardless of the type of guidance.

Despite these limitations, the present study attempts to extend the existing knowledge on ICBT by systematically investigating the effect of web-based clinicianguided peer-support. Thus, in conclusion, this study further supports the notion that SAD can be effectively treated via the internet with treatment gains maintained at sixmonth follow-up. The results suggest that a clinician-guided group format can be just as effective in alleviating symptoms specific to SAD as the individual format, while reducing clinician hours and potentially increasing cost-effectiveness. The online clinician-guided group format seems especially promising for the treatment of SAD because it enables patients to benefit from group processes without running the risk of overwhelming them. 


\section{Acknowledgements}

This study was funded by the Swiss National Science Foundation (personal grant TB:

PP00P1_144824/1). The authors would like to thank the participants in this trial for their involvement. 


\section{References}

Acarturk, C., Cuijpers, P., Van Straten, A., \& De Graaf, R. (2009). Psychological treatment of social anxiety disorder: a meta-analysis. Psychological Medicine, 39, 241-254.

American Psychiatric Association. (2013). Diagnostic and statistical manual of mental disorders. (5th ed.). Washington, DC: Author.

Andersson, G., Carlbring, P., Berger, T., Almlöv, J., \& Cuijpers, P. (2009). What makes Internet Therapy Work? Cognitive Behaviour Therapy, 38, 55-60.

Andersson, G., Carlbring, P., \& Furmark, T. on behalf of the SOFIE Research Group (2012). Therapist Experience and Knowledge Acquisition in Internet-Delivered CBT for Social Anxiety Disorder: A Randomized Controlled Trial. PLoS ONE, 7, 110.

Andersson, G., Carlbring, P., Holmström, A., Sparthan, E., Furmark, T., Nilsson-Ihrfelt, E., Buhrman, M., \& Ekselius, L. (2006). Internet-Based Self-Help With Therapist Feedback and In Vivo Group Exposure for Social Phobia: A Randomized Controlled Trial. Journal of Consulting and Clinical Psychology, 74, 677-686.

Andersson, G., Cuijpers, P., Carlbring, P., Riper, H., \& Hedman, E. (2014). Guided Internetbased vs. face-to-face cognitive behavior therapy for psychiatric and somatic disorders: a systematic review and meta-analysis. World Psychiatry, 13, 288-295.

Andersson, G., \& Hedman, E. (2013). Effectiveness of guided Internet-based cognitive behavior therapy in regular clinical settings. Verhaltenstherapie, 23(3), 140-148.

Andrews, G., Cuijpers, P., Craske, M. G., McEvoy, P., \& Titov, N. (2010). Computer therapy for the anxiety and depressive disorders is effective, acceptable and practical health care: A meta-analysis. PLoS ONE, 5.

Andrews, G., Davies, M., \& Titov, N. (2011). Effectiveness randomized controlled trial of face to face versus Internet cognitive behaviour therapy for social phobia. Australian and New Zealand Journal of Psychiatry, 45, 337-340.

Andrade, L. H., Alonso, J., Mneimneh, Z., Wells, J. E., Al-Hamzawi, A., Borges, G., ... \& Florescu, S. (2014). Barriers to mental health treatment: results from the WHO World Mental Health surveys. Psychological medicine, 44(06), 1303-1317.

Attkisson, C. C., \& Zwick, R. (1982). The client satisfaction questionnaire. Psychometric properties and correlations with service utilization and psychotherapy outcome. Evaluation and Program Planning, 5, 233-237.

Aydos, L., Titov, N., \& Andrews, G. (2009). Shyness 5: the clinical effectiveness of Internet-based clinician-assisted treatment of social phobia. Australasian Psychiatry, 17, 488-492.

Baumeister, H., Reichler, L., Munzinger, M., \& Lin, J. (2014). The impact of guidance on Internet-based mental health interventions-A systematic review. Internet Interventions, 1, 205-215.

Berger, T. (2011). Web 2.0 - Soziale Netzwerke und Psychotherapie. Psychotherapie im Dialog, 12, 118-122.

Berger, T. \& Andersson, G. (2009). Internet-based Psychotherapies: Characteristics and Empirical Evidence. Psychotherapie, Psychosomatik, Medizinische Psychologie, 59, 159-170.

Berger, T., Boettcher, J., \& Caspar, F. (2014). Internet-based guided self-help for several anxiety disorders: A randomized controlled trial comparing a tailored with a standardized disorder-specific approach. Psychotherapy, 51, 207.

Berger, T., \& Caspar, F. (2008). Von anderen Patienten lernen. Psychotherapeut, 53, 130137. 
Berger, T., Caspar, F., Richardson, R., Kneubühler, B., Sutter, D., \& Andersson, G. (2011). Internet-based treatment of social phobia: A randomized controlled trial comparing unguided with two types of guided self-help. Behaviour Research and Therapy, 49, 158-169.

Berger, T., Hämmerli, K., Gubser, N., Andersson, G., \& Caspar, F. (2011). Internet-based treatment of depression: a randomized controlled trial comparing guided with unguided self-help. Cognitive Behaviour Therapy, 40, 251-266.

Berger, T., Hohl, E., \& Caspar, F. (2009). Internet-Based Treatment for Social Phobia: A Randomized Controlled Trial. Journal of Clinical Psychology, 65, 1021-1035.

Berger, T., Hohl, E., \& Caspar, F. (2010). Internetbasierte Therapie der sozialen Phobie: Ergebnisse einer 6-Monate-Katamnese. Zeitschrift für Klinische Psychologie und Psychotherapie, 39, 217-221.

Beutler, L. E., \& Hamblin, D. L. (1986). Individualized outcome measures of internal change: Methodological considerations. Journal of Consulting and Clinical Psychology, 54, 48.

Boettcher, J., Berger, T., \& Renneberg, B. (2012). Does a pre-treatment diagnostic interview affect the outcome of Internet-based self-help for social anxiety disorder? A randomized controlled trial. Behavioural and Cognitive Psychotherapy, 40, 513-528.

Boettcher, J., Carlbring, P., Renneberg, B., \& Berger, T. (2013). Internet-Based Interventions for Social Anxiety Disorder - an Overview. Verhaltenstherapie, 23, 160-168.

Botella, C., Gallego, M. J., Garcia-Palacios, A., Guillen, V., Banos, R. M., Quero, S., \& Alcaniz, M. (2010). An Internet-Based Self-Help Treatment for Fear of Public Speaking: A Controlled Trial. Cyberpsychology, Behavior and Social Networking, 13(4), 407421.

Buntrock, C., Ebert, D. D., Lehr, D., Riper, H., Smit, F., Cuijpers, P., \& Berking, M. (2015). Effectiveness of a Web-Based Cognitive Behavioural Intervention for Subthreshold Depression: Pragmatic Randomised Controlled Trial. Psychotherapy and Psychosomatics, 84, 348-358.

Calear, A. L., Christensen, H., Mackinnon, A., \& Griffiths, K. (2013). Adherence to the MoodGYM program: outcome and predictors for an adolescent school-based population. Journal of Affective Disorders, 147, 338-344.

Carlbring, P., Gunnarsdottir, M., Hedensjö, L., Andersson, G., Ekselius, L., \& Furmark, T. (2007). Treatment of social phobia: randomised trial of Internet-delivered cognitive-behavioural therapy with telephone support. British Journal of Psychiatry, 190, 123-128.

Clarke, D. M., \& Wells, A. (1995). A cognitive model of social phobia. New York: Guilford Press.

Derogatis, L. R. (1993). BSI Brief Symptom Inventory: Administration, Scoring, and Procedure Manual (4th Edition ed.). Minneapolis, MN: National Computer Systems.

El Alaoui, S., Hedman, E., Kaldo, V., Hesser, H., Kraepelien, M., Andersson, E., ... \& Lindefors, N. (2015). Effectiveness of Internet-cased cognitive-behavior therapy for social anxiety disorder in clinical psychiatry. Journal of Consulting and Clinical Psychology, 83 (5), 902.

Eskildsen, A., Hougaard, E., \& Rosenberg, N. K. (2010). Pre-treatment patient variables as predictors of drop-out and treatment outcome in cognitive behavioral therapy for social phobia: A systematic review. Nordic Journal of Psychiatry, 64, 94-105. 
Faul, F., Erdfelder, E., Lang, A.-G., \& Buchner, A. (2007). G*Power 3: A flexible statistical power analysis program for the social, behavioral, and biomedical sciences. Behavior Research Methods, 41, 1149-1160.

Fehm, L., Pelissolo, A., Furmark, T., \& Wittchen, H.-U. (2005). Size and burden of social phobia in Europe. European Neuropsychopharmacology, 15, 453-462.

First, M. B., Spitzer, R. L., Gibbon, M., \& Williams, J. B. W. (1995). Structured clinical interview for DSM-IV Axis I disorders (SCID-I). Washington, DC: American Psychiatric Press.

Franke, G. H. (2000). BSI, Brief Symptom Inventory von L. R. Derogatis (Kurzform der SCL90-R) - deutsches Manual. Göttingen: Beltz Test GmbH.

Furmark, T., Carlbring, P., Hedman, E., Sonnenstein, A., Clevberger, P., Bohman, B., ... \& Sparthan, E. (2009). Guided and unguided self-help for social anxiety disorder: randomised controlled trial. British Journal of Psychiatry, 195, 440-447.

Gandek, B., Ware, J. E., Aaronson, N. K., Apolone, G., Bjorner, J. B., Brazier, J. E., ... \& Sullivan, M. (1998). Cross-Validation of Item Selection and Scoring for the SF-12 Health Survey in Nine Countries: Results from the IQOLA Project. Journal of Clinical Epidemiology, 51, 1171-1178.

Gross, R., Olfson, M., Gameroff, M. J., Shea, S., Feder, A., Lantigua, R., ... \& Weissman, M. M. (2005). Social anxiety disorder in primary care. General hospital psychiatry, 27, 161-168.

Gueorguieva, R., \& Krystal, J. H. (2004). Move over ANOVA. Progress in Analyzing Repeated-Measures Date and Its Reflection in Papers Published in the Archives of General Psychiatry. General Archives of General Psychiatry, 61, 310-317.

Hautzinger, M., Keller, F., \& Kühner, C. (2006). BDI-II Beck Depressions-Inventar. Frankfurt am Main: Harcourt Test Services.

Hedman, E., Andersson, E., Ljotsson, B., Andersson, G., Rück, C., \& Lindefors, N. (2011). Cost-effectiveness of Internet-based cognitive behavior therapy vs. cognitive behavioral group therapy for social anxiety disorder: Results from a randomized controlled trial. Behavior Research and Therapy, 49, 729-736.

Hedman, E., Andersson, G., Ljotsson, B., Andersson, E., Rück, C., Mörtberg, E., \& Lindefors, N. (2011). Internet-Based Cognitive Behavior Therapy vs. Cognitive Behavioral Group Therapy for Social Anxiety Disorder: A Randomized Controlled Noninferiority Trial. PLoS one, 6(3), e18001.

Hedman, E., Botella, C., \& Berger, T. (2016). Internet-Based Cognitive Behavior Therapy for Social Anxiety Disorder. In Guided Internet-Based Treatments in Psychiatry (pp. 53-78). Springer International Publishing.

Hedman, E., Furmark, T., Carlbring, P., Ljotsson, B., Rück, C., Lindefors, N., \& Andersson, G. (2011). A 5-Year Follow-up of Internet-Based Cognitive Behavior Therapy for Social Anxiety Disorder. J Med Internet Res, 13(2).

Hedman, E., Ljotsson, B., \& Lindefors, N. (2012). Cognitive behavior therapy via the Internet: a systematic review of applications, clinical efficacy and costeffectiveness. Expert Review of Pharmacoeconomics and Outcomes Research, 12, 745-764.

Hedman, E., Ljotsson, B., Rück, C., Furmark, T., Carlbring, P., Lindefors, N., \& Andersson, G. (2010). Internet administration of self-report measures commonly used in research on social anxiety disorder: A psychometric evaluation. Computers in Human Behavior, 26, 736-740.

Horowitz, L. M., Rosenberg, S. E., Baer, B. A., Ureno, G., \& Villasenor, V. S. (1988). Inventory of Interpersonal Problems: Psychometric Properties and Clinical Applications. Journal of Consulting and Clinical Psychology, 56, 885 - 892. 
Horowitz, L. M., Strauss, B., \& Kordy, H. (2000). Inventar zur Erfassung interpersonaler Probleme (IIP-D). Weinheim: Beltz.

Jacobson, N. S., \& Truax, P. (1991). Clinical Significance: A Statistical Approach to Defining Meaningful Chance in Psychotherapy Research. Journal of Consulting and Clinical Psychology, 59, 12-19.

Johansson, R., Sjöberg, E., Sjögren, M., Johnsson, E., Carlbring, P., Andersson, T., ... \& Andersson, G. (2012). Tailored vs. standardized Internet-based cognitive behavior therapy for depression and comorbid symptoms: a randomized controlled trial. PLoS one, 7(5), e36905.

Keller, M. (2003). The lifelong course of social anxiety disorder: a clinical perspective. Acta Psychiatrica Scandinavica, 108, 85-94.

Kessler, R. C., Berglund, P., Demler, O., Jin, R., Merikangas, K. R., \& Walters, E. E. (2005). Lifetime prevalence and age-of-onset distributions of DSM-IV disorders in the National Comorbidity Survey Replication. Archives of general psychiatry, 62, 593602.

Lee, B. W., \& Stapinski, L. A. (2012). Seeking safety on the Internet: Relationship between social anxiety and problematic Internet use. Journal of Anxiety Disorders, 26, 197205.

Lincoln, T. M., Rief, W., Hahlweg, K., Frank, M., von Witzleben, i., Schroeder, B., \& Fiegenbaum, W. (2003). Effectivess of an empirically supported treatment for social phobia in the field. Behavior Research and Therapy, 41, 1251-1269.

Mattick, R. P., \& Clarke, C. (1998). Development and validation of measures of social phobia scrutiny fear and social interaction anxiety. Behavior Research and Therapy, 36, 455-470.

Mayo-Wilson, E., Dias, S., Mavranezouli, I., Kew, K., Clark, D. M., Ades, A., \& Pilling, S. (2014). Psychological and pharmacological interventions for social anxiety disorder in adults: a systematic review and network meta-analysis. The Lancet Psychiatry, 1, 368-376.

Nordmo, M., Sinding, A. I., Carlbring, P., Andersson, G., Havik, O. E., \& Nordgreen, T. (2015). Internet-delivered cognitive behavioural therapy with and without an initial face-to-face psychoeducation session for social anxiety disorder: A pilot randomized controlled trial. Internet Interventions, 2(4), 429-436. doi: 10.1016/j.invent.2015.10.003

Olfson, M., Guardino, M., Struening, E., Schneier, F. R., Hellman, F., \& Klein, D. F. (2000). Barriers to the treatment of social anxiety. American Journal of Psychiatry, 157, 521-527.

Otto, M. W., Pollack, M. H., Gould, R. A., Worthington, J. J., McArdle, E., Rosenbaum, J., F., \& Heimberg, R. G. (2000). A Comparison of the Efficacy of Clonazepam and Cognitive-Behavioral Group Therapy for the Treatment of Social Phobia. Journal of Anxiety Disorders, 14, 345-358.

Richards, D., \& Richardson, T. (2012). Computer-based psychological treatments for depression: a systematic review and meta-analysis. Clinical Psychology Review, $32,329-342$.

Rohde, P., Lewinsohn, P. M., \& Seeley, J. R. (1997). Comparability of telephone and faceto-face interviews in assessing axis I and II disorders. American Journal of Psychiatry, 154, 1593-1598.

Schmidt, J., Lamprecht, F., \& Wittmann, W. W. (1989). Zufriedenheit mit der stationären Versorung. Entwicklung eines Fragebogens und erste Validitätsuntersuchungen. Psychotherapie Psychosomatik Medizinische Psychologie, 39, 248-255. 
Schulz, A., Stolz, T., \& Berger, T. (2014). Internet-based individually versus group guided self-help treatment for social anxiety disorder: protocol of an randomized controlled trial. BMC Psychiatry, 14(1), 1.

Shafran, R., Clark, D. M., Fairburn, C. G., Arntz, A., Barlow, D. H., Ehlers, A., ... Wilson, G. T. (2009). Mind the gap: Improving the dissemination of CBT. Behaviour Research and Therapy, 47(11), 902-909.

Steketee, G., \& Chambless, D. L. (1992). Methodological issues in prediction of treatment outcome. Clinical Psychology Review, 12, 387-400.

Spek, V., Cuijpers, P., Nyklicek, I., Riper, H., Keyzer, J., \& Pop, V. (2007). Internet-based cognitive behaviour therapy for symptoms of depression and anxiety: a metaanalysis. Psychological Medicine, 37, 319-328.

Stangier, U., Heidenreich, T., Berardi, A., Golbs, U., \& Hoyer, J. (1999). Die Erfassung sozialer Phobie durch die Social Interaction Anxiety Scale (SIAS) und die Social Phobia Scale (SPS). Zeitschrift für Klinische Psychologie, 28, 28-36.

Stangier, U., Heidenreich, T., Peitz, M., Lauterbach, W., \& Clark, D. M. (2003). Cognitive therapy for social phobia: individual versus group treatment. Behaviour Research and Therapy, 41, 991-1007.

Stein, M. B., \& Kean, Y. M. (2000). Disability and quality of life in social phobia: epidemiologic findings. American Journal of Psychiatry, 157, 1606-1613.

Titov, N., Andrews, G., Choi, I., Schwencke, G., \& Johnston, L. (2009). Randomized controlled trial of web-based treatment of social phobia without clinician guidance. Australian and New Zealand Journal of Psychiatry, 43, 913-919.

Titov, N., Andrews, G., Choi, I., Schwencke, G., \& Mahoney, A. (2008). Shyness 3: An RCT of guided versus unguided Internet based CBT for social phobia. Australian and New Zealand Journal of Psychiatry, 42, 1030-1040.

Titov, N., Andrews, G., Schwencke, G., Drobny, J., \& Einstein, D. (2008). Shyness 1: distance treatment of social phobia over the Internet. Australian and New Zealand Journal of Psychiatry, 42, 585-594.

Titov, N., Andrews, G., Schwencke, G., Solley, K., Johnston, L., \& Robinson, E. (2009). An RCT comparing effect of two types of support on severity of symptoms for people completing Internet-based cognitive behaviour therapy for social phobia. Australian and New Zealand Journal of Psychiatry, 43, 920-926.

Titov, N., Gibson, M., Andrews, G., \& McEvoy, P. (2009). Internet treatment for social phobia reduces comorbidity. Australian and New Zealand Journal of Psychiatry, 43, 754-759.

Tulbure, B. T., Szentagotai, A., David, O., Ștefan, S., Månsson, K. N., David, D., \& Andersson, G. (2015). Internet-Delivered Cognitive-Behavioral Therapy for Social Anxiety Disorder in Romania: A Randomized Controlled Trial. PloS one, 10(5), e0123997.

Wittchen, H.-U., Zaudig, M., \& Fydrich, T. (1997). Strukturiertes Klinisches Interview für DSM-IV. Göttingen: Hogrefe.

Yonkers, K. A., Dyck, I. R., \& Keller, M. B. (2001). An eight-year longitudinal comparison of clinical course and characteristics of social phobia among men and women. Psychiatric Services. 
Table 1

Content of the Internet-based self-help program for SAD (Berger, Boettcher, \& Caspar, 2014)

Session 1: Motivational enhancement

Session 2: Psychoeducation

Session 3: Cognitive restructuring

Session 4: Self-focused attention

Session 5: Behavioural experiments

Session 6: Summary and repetition

Session 7: Healthy lifestyle and problem solving

Session 8: Relapse prevention
Reason to initiate change, goal definition, recording of difficult situations Information on SAD and its maintaining processes such as negative beliefs, selffocused attention and safety behaviours Identification and modification of dysfunctional assumptions using a thought diary Various exercises to reduce self-focused attention, e.g. short behavioural experiments

Planning and implementing in vivo exposures

Summary of key elements of the treatment with emphasis on the importance of repeated practice (e.g. in vivo exposure)

Information of healthy lifestyle behaviour (physical exercise and nutrition)

Strategies for maintaining the skills learned, preparation for possible relapse 
Table 2

Demographic description of the sample

\begin{tabular}{|c|c|c|c|c|}
\hline & $\begin{array}{l}\mathrm{IT} \\
(n=60)\end{array}$ & $\begin{array}{l}\mathrm{GT} \\
(n=60)\end{array}$ & $\begin{array}{l}\mathrm{WL} \\
(n=29)\end{array}$ & $\begin{array}{l}\text { Total } \\
(n=149)\end{array}$ \\
\hline \multicolumn{5}{|l|}{ Gender } \\
\hline Male & $27(45 \%)$ & $30(50 \%)$ & $13(44.8 \%)$ & $70(47 \%)$ \\
\hline Female & $33(55 \%)$ & $30(50 \%)$ & $16(55.2 \%)$ & $79(53 \%)$ \\
\hline \multicolumn{5}{|l|}{ Age } \\
\hline Mean age (SD) & 36.05 & $35.82(11.42)$ & 33.07 (10.74) & 35.38 (11.16) \\
\hline Min-Max & $\begin{array}{l}(11.12) \\
20-62\end{array}$ & $18-76$ & $20-65$ & $18-76$ \\
\hline \multicolumn{5}{|l|}{ Marital status } \\
\hline Single & $31(51.7 \%)$ & $30(50 \%)$ & $16(55.2 \%)$ & $77(51.7)$ \\
\hline Married/living together & $25(41.7 \%)$ & $25(41.7 \%)$ & $11(37.9 \%)$ & $61(40.9 \%)$ \\
\hline Divorced & $4(6.7 \%)$ & $5(8.3 \%)$ & $1(3.4 \%)$ & $10(6.75)$ \\
\hline Widowed & $0(0 \%)$ & $0(0 \%)$ & $1(3.4 \%)$ & $1(0.7 \%)$ \\
\hline \multicolumn{5}{|l|}{ Highest education } \\
\hline Compulsory school & $3(5.0 \%)$ & $1(1.7 \%)$ & $1(3.4 \%)$ & $5(3.4 \%)$ \\
\hline Apprenticeship & $16(26.7 \%)$ & 19 (31.7\%) & $6(20.7 \%)$ & $41(27.5 \%)$ \\
\hline High School & $16(26.7 \%)$ & $17(28.3 \%)$ & $7(24.15 \%)$ & $40(6.8 \%)$ \\
\hline University & $25(41.7 \%)$ & $23(38.3 \%)$ & $15(51.7 \%)$ & $63(42.3 \%)$ \\
\hline \multicolumn{5}{|l|}{ Employment } \\
\hline Full time employed & 29 (48.3\%) & 24 (40.0\%) & $10(34.5 \%)$ & $63(42.3 \%)$ \\
\hline Part time employed & $14(23.3 \%)$ & $11(18.3 \%)$ & $2(6.9 \%)$ & $27(18.1 \%)$ \\
\hline Student & $10(16.7 \%)$ & $14(23.3 \%)$ & $11(37.9 \%)$ & 35 (23.5\%) \\
\hline Unemployed & 5 (8.3\%) & $8(13.3 \%)$ & $4(13.8 \%)$ & $17(11.4 \%)$ \\
\hline Retired & $2(3.3 \%)$ & $3(5.0 \%)$ & $2(6.9 \%)$ & $7(4.7 \%)$ \\
\hline \multicolumn{5}{|l|}{ Treatment history } \\
\hline None & $22(36.7 \%)$ & $31(51.7 \%)$ & $12(41.4 \%)$ & $65(43.6 \%)$ \\
\hline Past & $38(63.3 \%)$ & $29(48.3 \%)$ & $17(58.6 \%)$ & $84(56.4 \%)$ \\
\hline \multicolumn{5}{|l|}{ Medication } \\
\hline None & $52(86.7 \%)$ & $51(85.0 \%)$ & $26(89.6 \%)$ & $129(86.6 \%)$ \\
\hline Present & $8(13.3 \%)$ & $9(15.0 \%)$ & $3(10.3 \%)$ & $20(13.4 \%)$ \\
\hline \multicolumn{5}{|c|}{ Number of comorbid diagnoses } \\
\hline none & 32 (53.3\%) & $31(51.7 \%)$ & $14(48.3 \%)$ & 77 (51.7\%) \\
\hline one & 19 (31.7\%) & 17 (28.3\%) & $11(37.9 \%)$ & 47 (31.5\%) \\
\hline two & $8(5.4 \%)$ & $11(18.3 \%)$ & $3(10.3 \%)$ & $22(14.8 \%)$ \\
\hline three & $1(1.7 \%)$ & $1(1.7 \%)$ & $1(0.7 \%)$ & $3(2 \%)$ \\
\hline \multicolumn{5}{|l|}{ Comorbid diagnoses } \\
\hline specific phobias & $11(18.3 \%)$ & $11(18.3 \%)$ & $2(6.9 \%)$ & $24(16.1 \%)$ \\
\hline current MDE & $8(13.3 \%)$ & $10(16.7 \%)$ & $5(17.24 \%)$ & $23(15.4 \%)$ \\
\hline dysthymia & $8(13.3 \%)$ & $6(10 \%)$ & $6(20.7 \%)$ & 20 (13.4\%) \\
\hline GAD & $3(5 \%)$ & $7(11.7 \%)$ & $1(3.5 \%)$ & $11(7.4 \%)$ \\
\hline PDA & $3(5 \%)$ & $3(5 \%)$ & $1(3.5 \%)$ & $7(4.7 \%)$ \\
\hline OCD & $1(1.7 \%)$ & $3(5 \%)$ & $1(3.5 \%)$ & $5(3.4 \%)$ \\
\hline alcohol abuse/addiction & $3(5 \%)$ & $0(0 \%)$ & $2(6.9 \%)$ & $5(3.4 \%)$ \\
\hline
\end{tabular}


Notes. IT = clinician-guided individual treatment; GT = clinician-guided group treatment; WL = wait-list, $\mathrm{MDE}=$ major depressive episode, GAD = generalized anxiety disorder, PDA = panic disorder with/without agoraphobia, $O C D=$ obsessive-compulsive disorder. 
Table 3

Observed and estimated means for primary and secondary outcome measures, overall effects and post-treatment between-group comparisons

\begin{tabular}{|c|c|c|c|c|c|c|c|c|c|}
\hline \multirow[b]{2}{*}{ Measure } & \multicolumn{2}{|l|}{ Pre-treatment } & \multicolumn{2}{|l|}{$\begin{array}{l}\text { Post-treatment } \\
\text { (observed) }\end{array}$} & \multirow{2}{*}{$\begin{array}{l}\begin{array}{l}\text { Post-treatment } \\
\text { (estimated) }\end{array} \\
M(S E) \\
\end{array}$} & \multicolumn{2}{|l|}{$\begin{array}{l}\text { Follow-up } \\
\text { (observed) }\end{array}$} & \multirow{2}{*}{$\begin{array}{l}\text { Overall effects at post- } \\
\text { treatment } \\
\text { (group by time interactions) } \\
F \text { and df }\end{array}$} & \multirow[t]{2}{*}{$\begin{array}{l}\text { Post-treatment } \\
\text { between-group } \\
\text { comparisons }^{\mathrm{a}} \\
\end{array}$} \\
\hline & $M(S D)$ & $n$ & $M(S D)$ & $n$ & & $M(S D)$ & $n$ & & \\
\hline \multicolumn{10}{|l|}{ SPS } \\
\hline IT & $39.32(11.64)$ & 60 & $21.07(10.94)$ & 46 & $21.69(1.78)$ & $20.61(11.85)$ & 32 & \multirow{3}{*}{$\begin{array}{l}F_{2,122.45}=15.17 \\
p<.001\end{array}$} & \multirow{3}{*}{$\begin{array}{l}\text { IT vs. WL: } p<.001 \\
\text { GT vs. WL: } p=.002 \\
\text { IT vs. GT: } p=.63\end{array}$} \\
\hline GT & $38.90(14.04)$ & 60 & $23.78(13.16)$ & 45 & $24.88(1.80)$ & $20.66(10.49)$ & 31 & & \\
\hline WL & $37.35(12.45)$ & 29 & $34.58(12.30)$ & 24 & $35.63(2.49)$ & & & & \\
\hline \multicolumn{10}{|l|}{ SIAS } \\
\hline IT & $50.48(14.48)$ & 60 & $33.87(14.47)$ & 46 & $34.82(2.02)$ & 32.36 (15.38) & 32 & \multirow{3}{*}{$\begin{array}{l}\mathrm{F}_{2,119.92}=8.10 \\
p=.001\end{array}$} & \multirow{3}{*}{$\begin{array}{l}\text { IT vs. WL: } p=.001 \\
\text { GT vs. WL: } p=.007 \\
\text { IT vs. GT: } p=.99\end{array}$} \\
\hline GT & $50.93(14.00)$ & 60 & $36.56(16.01)$ & 45 & $36.66(2.04)$ & 34.28 (16.09) & 31 & & \\
\hline WL & $50.97(13.58)$ & 29 & 47.67 (10.97) & 24 & $47.44(2.83)$ & & & & \\
\hline \multicolumn{10}{|c|}{ 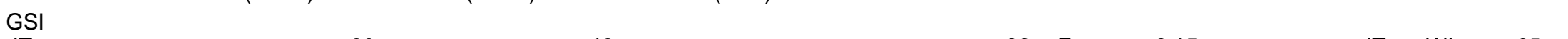 } \\
\hline IT & $1.28(0.54)$ & 60 & $0.89(0.59)$ & 46 & $0.75(0.08)$ & $0.75(0.48)$ & 32 & \multirow{3}{*}{$\begin{array}{l}\mathrm{F}_{2,118.36}=6.15 \\
p=.003\end{array}$} & \multirow{3}{*}{$\begin{array}{l}\text { IT vs. WL: } p=.05 \\
\text { GT vs. WL: } p=.04 \\
\text { IT vs. GT: } p=.99\end{array}$} \\
\hline GT & $1.30(0.65)$ & 60 & $0.88(0.60)$ & 45 & $0.74(0.08)$ & $0.74(0.62)$ & 31 & & \\
\hline WL & $1.25(0.64)$ & 29 & $1.13(0.73)$ & 24 & $1.09(0.12)$ & & & & \\
\hline \multicolumn{10}{|l|}{ BDI-II } \\
\hline IT & $19.43(10.22)$ & 60 & $10.35(10.22)$ & 46 & $10.49(1.46)$ & $11.13(10.80)$ & 32 & \multirow{3}{*}{$\begin{array}{l}F_{2,119.86}=3.60 \\
p=.03\end{array}$} & \multirow{4}{*}{$\begin{array}{l}\text { IT vs. WL: } p=.29 \\
\text { GT vs. WL: } p=.18 \\
\text { IT vs. GT: } p=.99\end{array}$} \\
\hline GT & $17.88(10.46)$ & 60 & $10.27(9.87)$ & 45 & $9.91(1.47)$ & $11.16(10.66)$ & 31 & & \\
\hline WL & $17.97(11.59)$ & 29 & $14.41(11.42)$ & 24 & $14.67(2.04)$ & & & & \\
\hline \multicolumn{9}{|c|}{ - } & \\
\hline IT & $1.91(0.45)$ & 60 & $1.46(0.55)$ & 46 & $1.48(0.07)$ & $1.38(0.62)$ & 32 & \multirow{3}{*}{$\begin{array}{l}F_{2,122.97}=8.14 \\
p<.001\end{array}$} & \multirow{3}{*}{$\begin{array}{l}\text { IT vs. WL: } p=.13 \\
\text { GT vs. WL: } p=.07 \\
\text { IT vs. GT: } p=.99\end{array}$} \\
\hline GT & $1.81(0.52)$ & 60 & $1.44(0.55)$ & 45 & $1.44(0.07)$ & $1.44(0.62)$ & 31 & & \\
\hline WL & $1.75(0.55)$ & 29 & $1.70(0.55)$ & 24 & $1.75(0.10)$ & & & & \\
\hline \multicolumn{10}{|l|}{ SF-12pH } \\
\hline IT & $51.98(9.04)$ & 60 & $50.58(9.63)$ & 46 & $50.87(1.18)$ & $50.90(8.91)$ & 32 & \multirow{3}{*}{$\begin{array}{l}F_{2,122.70}=0.22 \\
p=.80\end{array}$} & \multirow{3}{*}{$\begin{array}{l}\text { IT vs. WL: } p=.99 \\
\text { GT vs. WL: } p=.99 \\
\text { IT vs. GT: } p=.31\end{array}$} \\
\hline GT & $53.75(7.53)$ & 60 & $53.84(5.80)$ & 45 & $53.60(1.19)$ & $53.65(5.97)$ & 31 & & \\
\hline WL & $52.73(9.75)$ & 29 & $52.27(9.19)$ & 24 & $52.29(1.66)$ & & & & \\
\hline \multicolumn{10}{|l|}{ SF-12MH } \\
\hline IT & $31.92(9.62)$ & 60 & 41.09 (10.72) & 46 & $41.11(1.53)$ & $39.49(10.56)$ & 32 & \multirow{3}{*}{$\begin{array}{l}F_{2,122.24}=3.66 \\
p=.029\end{array}$} & \multirow{3}{*}{$\begin{array}{l}\text { IT vs. WL: } p=.97 \\
\text { GT vs. WL: } p=.35 \\
\text { IT vs. GT: } p=.99\end{array}$} \\
\hline GT & $32.66(10.34)$ & 60 & $42.19(12.17)$ & 45 & $42.68(1.54)$ & $40.95(13.32)$ & 31 & & \\
\hline WL & $35.11(10.67)$ & 29 & $38.88(11.27)$ & 24 & $38.52(2.13)$ & & & & \\
\hline
\end{tabular}

Notes. IT = clinician-guided individual treatment; GT = clinician-guided group treatment; WL = wait-list; SPS = Social Phobia Scale; SIAS = Social Interaction Anxiety Scale; GSI = Global Severity Index (Brief Symptom Inventory); BDI-II: Beck Depression Inventory-Second edition; IIP: Inventory of Interpersonal Problems; SF-12PH = Short Form Health Survey physical health subscale; SF-12 $\mathrm{MH}=$ Short Form Health Survey mental health subscale

a Intention to treat (ITT) analysis 
Table 4

Within and between-group effect sizes at post-treatment, follow-up (Cohen's d)

\begin{tabular}{|c|c|c|c|c|c|c|c|c|c|}
\hline & \multicolumn{3}{|c|}{$\begin{array}{l}\text { Within-group effect sizes } \\
\text { (estimated means) } \\
\text { Cohen's d }(95 \% \mathrm{Cl})\end{array}$} & \multicolumn{3}{|c|}{$\begin{array}{l}\text { Between-group effect sizes at post-treatment } \\
\text { (estimated means) } \\
\text { Cohen's d }(95 \% \mathrm{Cl})\end{array}$} & \multicolumn{3}{|c|}{$\begin{array}{l}\text { Effect sizes at follow-up } \\
\text { (estimated means) } \\
\text { Cohen's d }(95 \% \mathrm{Cl})\end{array}$} \\
\hline & IT & GT & $\mathrm{WL}$ & IT vs. GT & IT vs. WL & GT vs. WL & IT & GT & IT vs. GT \\
\hline SPS & $1.50(1.10-1.91)$ & $1.03(0.65-1.41)$ & $0.14(-0.38-0.65)$ & $0.26(-0.10-0.63)$ & $1.22(0.75-1.70)$ & $0.84(0.37-1.29)$ & $1.55(1.15-1.96)$ & $1.33(0.93-1.73)$ & $0.12(-0.24-0.48)$ \\
\hline SIAS & $1.08(0.70-1.47)$ & $0.95(0.57-1.33)$ & $0.28(-0.23-0.80)$ & $0.12(-0.24-0.48)$ & $0.94(0.48-1.40)$ & $0.74(0.28-1.20)$ & $1.10(0.71-1.48)$ & $1.07(0.69-1.45)$ & $0.04(-0.31-0.40)$ \\
\hline GSI & $0.94(0.56-1.31)$ & $0.90(0.52-1.27)$ & $0.23(-0.28-0.75)$ & $-0.02(-0.38-0.34)$ & $0.53(0.08-0.98)$ & $0.54(0.09-0.99)$ & $0.98(0.60-1.36)$ & $0.80(0.43-1.18)$ & $0.02(-0.34-0.38)$ \\
\hline BDI-II & $0.88(0.5-1.25)$ & $0.78(0.41-1.16)$ & $0.29(-0.23-0.80)$ & $-0.06(-0.42-0.30)$ & $0.40(-0.05-0.84)$ & $0.46(0.01-0.91)$ & $0.70(0.34-1.07)$ & $0.56(0.20-0.93)$ & $-0.01(-0.37-0.35)$ \\
\hline IIP & $0.86(0.48-1.23)$ & $0.69(0.32-1.06)$ & $0.00(-0.52-0.52)$ & $-0.07(-0.43-0.29)$ & $0.49(0.40-0.94)$ & $0.56(0.11-1.02)$ & $0.98(0.60-1.36)$ & $0.63(0.26-1.00)$ & $0.11(-0.25-0.47)$ \\
\hline SF-12PH & $-0.12(-0.47-0.24)$ & $-0.02(-0.38-0.34)$ & $-0.05(-0.56-0.47)$ & $0.34(-0.02-0.70)$ & $0.15(-0.29-0.59)$ & $0.19(-0.63-0.26)$ & $-0.12(-0.24-0.48)$ & $-0.18(-0.55-0.17)$ & $-0.21(-0.56-0.15)$ \\
\hline SF-12MH & $0.90(0.53-1.28)$ & $0.89(0.51-1.26)$ & $0.31(-0.21-0.83)$ & $0.14(-0.22-0.50)$ & $0.24(-0.68-0.21)$ & $0.35(-0.78-0.11)$ & $0.74(0.37-1.11)$ & $0.66(0.29-1.03)$ & $-0.10(-0.46-0.26)$ \\
\hline
\end{tabular}

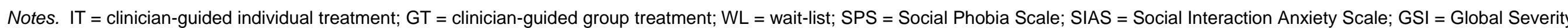

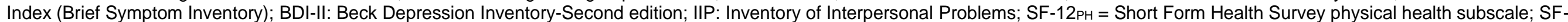
$12 \mathrm{mH}=$ Short Form Health Survey mental health subscale 
667 individuals applied to participate via our homepage

463 did not send in written consent via mail or did not fill out the questionnaires

204 individuals signed informed consent \& filled out questionnaires

164 individuals completed the SKID interview by telephone
Do not fulfill initial inclusion criteria $(n=40)$

on-going psychological treatment $(n=13)$

- not reached for SCID interview $(n=5)$

- do not exceed cutoff in SPS and SIAS ( $n=22)$

149 individuals met all inclusion criteria and were randomized

Excluded after SKID interview $(n=15)$

- no SAD according to SCID $(n=9)$

- unstable medication $(n=4)$

- suicidal ideation / referral to local psych. $(n=2)$
Clinician-guided group treatment $(n=60)$

\section{Completed} post-treatment questionnaires $(n=46)$ $\operatorname{SCID}(n=36)$

\section{Completed}

6 month follow-up questionnaires $(n=32)$ $\operatorname{SCID}(n=26)$

\section{Clinician-guided individual treatment $(n=60)$}

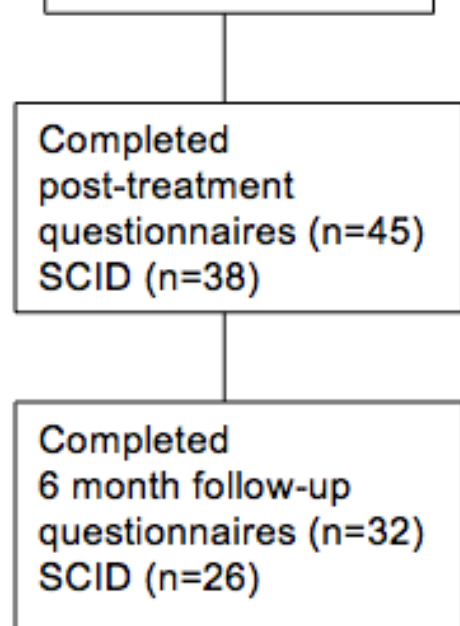

Wait-list $(n=29)$

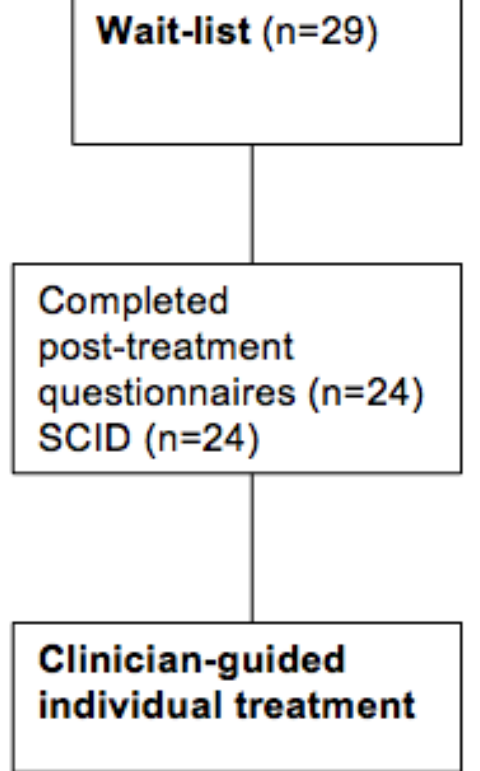

Figure 1. Participant flow 